\title{
Studi Desain Reklamasi Dengan Timbunan Bertahap dan Prefabricated Vertical Drain dengan Metode Elemen Hingga
}

\author{
Anthonius ONGGO ${ }^{1} \cdot$ Simon Dertha TARIGAN ${ }^{2} *$ \\ ${ }^{1}$ Program Studi Teknik Sipil Universitas Katolik Santo Thomas \\ ${ }^{2}$ Staf Pengajar Teknik Sipil Universitas Katolik Santo Thomas
}

\begin{abstract}
Soft clay substantial settlement and requires longer time to finish consolidation. The observed project in this study is reclamation project. Reclamation is carried out with a gradual piling method so that the strength gain occurs in the soil layer under reclaimed soil. Piling is done repeatedly, with an initial elevation of $+2 m$, second piling with a total elevation of $+5 m$, and the third piling with a total elevation $+8 m A S L$. Piling material in this project is compacted sand material, with specified specifications. The use of sand material results in the potential for liquefaction. Therefore it is necessary to conduct soil improvement, and PVD with preloading is chosen which is useful for accelerating the consolidation time. The Prefabricated Vertical Drain method is installed along the reclamation area. This study aims to analyze the soil settlement over time both using PVD and without using PVD. The effect of PVD installation by preloading was analyzed using PLAXIS $2 D$ with axisymmetric for single-drain, and was further modeled in multi drain using plane strain. Single drain modeling into multi drain needs to be done axisymmetic equivalence to plane strain. The soil parameters used are the results of the N-SPT value correlation from various sources.
\end{abstract}

Kata kunci: Prefabricated Vertical Drain, PLAXIS, Reklamasi

\section{Pendahuluan}

Kebutuhan akan lahan atau tanah tidak bisa dielakkan lagi keberadaannya karena tanah merupakan kebutuhan utama dalam pelaksanaan pembangunan, karena itu sebelum pelaksanaan suatu pembangunan harus ada terlebih dahulu tersedianya komponen yang paling prinsip yang dinamakan tanah atau lahan. Tanpa adanya komponen yang utama ini, maka pembangunan tidak akan bisa diwujudkan. Tanah yang ada di perkotaan lebih dititikberatkan pada penggunaannya untuk keperluan mendirikan bangunan daripada untuk keperluan pertanian, peternakan, perikanan, dan perkebunan. Bangunan tersebut dapat berupa perumahan, toko, rumah toko (ruko), rumah kantor (rukan), rumah sakit, hotel, pabrik, gudang, gedung olahraga, gedung perkantoran, pasar/plaza/mall, terminal, pelabuhan,dll.

Pada era globalisasi ini kebutuhan atau permintaan terhadap area lahan semakin bertambah, di mana semakin bertambahnya penduduk merupakan salah satu faktor pemicu semakin banyaknya lahan yang diperlukan, baik untuk keperluan tempat tinggal maupun untuk keperluan tempat kegiatan usaha. Permintaan kebutuhan akan lahan tidak seimbang dengan area lahan atau tanah yang tersedia, sehingga persediaan lahan atau tanah semakin sempit dan bahkan semakin berkurang.

Semakin banyaknya permintaan area lahan atau tanah tersebut mendorong Negara melalui Pemerintah berusaha memenuhi kebutuhan atas tanah dengan alternatif yakni pemekaran

*penulis korespondensi

e-mail:simondertha2003@yahoo.com 
vertikal dengan membangun gedung-gedung pencakar langit dan rumah-rumah susun. Dengan pembangunan gedung bertingkat, penggunaan tanah akan lebih optimal, efektif, dan efisien. Selain dengan pembangunan gedung bertingkat, upaya yang dapat dilakukan untuk memenuhi kebutuhan akan tanah adalah dengan mengubah wilayah pantai menjadi daratan baru yang dikenal dengan kegiatan gambar reklamasi pantai.

\section{Tinjauan Pustaka}

\section{Parameter Tanah}

Tanah adalah campuran butir-butir dari berbagai ukuran dan bahwa ada hubungan yang erat antara penyebaran besar butir dan sifat tanah. Para ahli menyatakan berat tanah dalam istilah kerapatan butir-butir yang menyusun tanah. Biasanya ditetapkan sebagai massa atau berat satuan solum tanah padat dan disebut kerapatan butir. Dalam sistem metrik kerapatan butir biasanya dinyatakan dengan istilah gram per sentimeter kubik. Jadi, satu sentimeter kubik tanah padat beratnya 2,6 gram kerapatan butir ialah 2,6 gram per sentimeter kubik.

Meskipun terdapat kisaran besar dalam kisaran kerapatan mineral tanah, gambaran untuk kebanyakan tanah mineral biasanya bervariasi antara batas yang sempit yaitu antara 2,60 sampai 2,75 gram persentimeter kubik.

Parameter tanah merupakan hal yang penting dalam melakukan desain sebuah reklamasi, dan sangat berhubungan terhadap karakteristik tanah. Dengan memiliki parameter tanah, dapat diketahui kekuatan tanah, bidang runtuh tanah, kekakuan tanah, dan sebagainya yang kemudian akan digunakan untuk proses-proses perhitungan selanjutnya.

Data tanah didapatkan melalui beberapa cara, dua diantaranya adalah melalui tes lapangan, dan tes lab, kemudian data tanah yang ada diolah menggunakan rumus korelasi, sehingga diperoleh parameter tanah. Pada Tugas Akhir ini, beberapa data tanah telah disediakan oleh konsultan yang melakukan soil investigation, dan yang tidak disediakan akan dihitung menggunakan rumus korelasi. Uji lapangan yang telah dilakukan ialah Standard Penetration Test (SPT) dan Cone Penetration Test (CPT).

Tanah secara umum, dibedakan menjadi 2, yaitu:

1. Tanah kohesif dan tidak kohesif

Tanah disebut kohesif yaitu apabila karakteristik fisiknya yang selalu melekat antara butiran tanah sewaktu pembasahan dan/atau pengeringan. Butiran-butiran tanah bersatu sesamanya, sehingga sesuatu gaya akan diperlukan untuk memisahkannya dalam keadaan kering. Sedangkan pada tanah non kohesif butiran tanah terpisahpisah sesudah dikeringkan dan melekat hanya apabila berada dalam keadaan basah akibat gaya tarik permukaan didalam air, misalnya pasir.

2. Plastisitas dan konsistensi tanah kohesif

Salah satu karakteristik tanah berbutir halus yang kohesif adalah Plastisitas, yaitu kemampuan butiran untuk tetap melekat satu sama lain. Batas-batas keplastisan tanah bergantung pada sejarah terjadinya dan komposisi mineral yang dikandungnya.Untuk mendefinisikan plastisitas tanah kohesif, diperlukan kondisi fisik tanah tersebut pada kadar air tertentu yang disebut konsistensi. Konsistensi tanah kohesif pada kondisi alamnya dinyatakan dalam istilah lunak, sedang dan kaku. 


\section{Undrained Shear Strength (Cu)}

Kekuatan geser pada tanah lempung didominasi dengan kohesi (c) atau kekuatan tekan tak tersekap (unconfined compressive strength), yaitu Qu. Khusus untuk undrained shear strength $(\mathrm{Su})$, diperoleh dari pengujian triaksial UU (unconsolidated undrained triaxial test) maupun unconfined compressive strength (UCS). Adapun harga Su dari UCS yang menghasilkan harga Qu, yaitu :

$$
S t=\frac{1}{2} \times Q u
$$

Tabel 1 Unconfined Compressive Strength berbagaiTanah (Terzaghi \& Peck 1967)

\begin{tabular}{|l|l|l|}
\hline Consistency & SPT $-\boldsymbol{N}$ & $\mathbf{Q u}(\boldsymbol{k P a})$ \\
\hline Very soft & $<2$ & $<25$ \\
Soft & $2-4$ & $25-50$ \\
Medium & $4-8$ & $50-100$ \\
Stiff & $8-15$ & $100-200$ \\
Very stiff & $15-30$ & $200-400$ \\
Hard & $>30$ & $>400$ \\
\hline
\end{tabular}

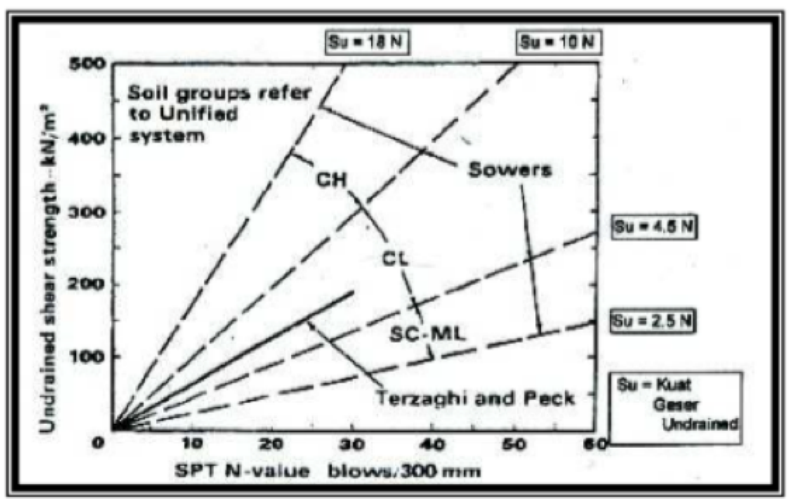

Gambar 1 Su vs N-SPT (1) (Terzaghi \& Peck, 1967; Sowers, 1979)

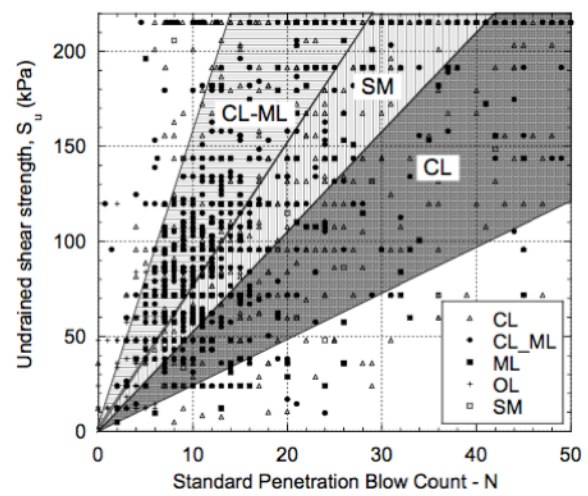

Gambar 2 Su vs N-SPT (2) (Terzaghi \& Peck, 1967)

\section{Undrained Shear Strength (Cu)}

Berat jenis tanah adalah perbandingan antara berat tanah kering utuh (undisturbed) dengan volum partikel yang termasuk juga volum ruang pori antar partikelnya.

$$
\gamma=\frac{\text { berat } W}{\text { Vulam }(W)}\left(\frac{k N}{m \cdot 2}\right)
$$


Nilai berat jenis tanah ini berkaitan erat dengan nilai densitas, yaitu :

$$
\gamma=\frac{y-\text { dentsitas ip! }}{1000}\left(\frac{k . Y}{\ln 3}\right)
$$

(Pers. 2.3)

Tabel 2 Hubungan antara harga $\mathrm{N}$ dan berat isi $\left(\gamma_{\mathrm{unsat}}\right)$

\begin{tabular}{|l|l|l|l|l|l|}
\hline \multirow{2}{*}{$\begin{array}{l}\text { Tanah kohesif } \\
\text { kndak }\end{array}$} & Harga N & $<10$ & $10-30$ & $30-50$ & $>50$ \\
\cline { 2 - 6 } & $\begin{array}{l}\text { Berat isi Y } \\
(\mathrm{kN} / \mathrm{m} 3)\end{array}$ & $12-16$ & $14-18$ & $16-20$ & $18-23$ \\
\hline \multirow{2}{*}{ Tanah kohesif } & Harga N & $<4$ & $\begin{array}{l}4-6 / 6- \\
15\end{array}$ & $16-25$ & $>25$ \\
\cline { 2 - 6 } & $\begin{array}{l}\text { Berat isi Y } \\
(\mathrm{kN} / \mathrm{m} 3)\end{array}$ & $14-18$ & $16-18$ & $16-18$ & $>20$ \\
\hline
\end{tabular}

(Sumber: Sosrodarsono, 1977)

Tabel 3 Hubungan antara $\mathrm{N}$ dan berat isi $\left(\gamma_{\text {sat }}\right)$

\begin{tabular}{|l|l|l|l|}
\hline N-SPT & Konsistensi & $\mathrm{Qu}$ & $\gamma$ sat KN $/ \mathrm{m}^{3}$ \\
\hline$<2$ & Very Soft & $<0.25$ & $16-19$ \\
\hline $2-4$ & Soft & $0.25-0.50$ & $16-19$ \\
\hline $4-8$ & Medium & $0.50-1.00$ & $17-20$ \\
\hline $8-15$ & Stiff & $1.00-2.00$ & 1922 \\
\hline $15-30$ & Very Stiff & $2.00-4.00$ & $19-22$ \\
\hline$>30$ & Hard & $>4.00$ & $19-22$ \\
\hline
\end{tabular}

\section{Sudut Geser}

Sudut geser tanah merupakan tahanan terhadap pengeseran antara partikel tanah.Nilai sudut geser ini beserta nilai kohesi mempengaruhi nilai kekuatan geser tanah tersebut. Seperti yang kita ketahui bahwa kuat geser tanah adalah gaya perlawanan yang dilakukan oleh butir tanah terhadap desakan atau tarikan. Nilai kekuatan geser tanah menunjukkan besarnya kekuatan daya dukung tanah tersebut.

Persamaan korelasi antara sudut geser dengan nilai N-SPT ada beberapa, yaitu :

a. Shioi dan Fukui (1982)

$$
\text { b }=(10 \times N)^{0.3}+15
$$

b. Japan Road Association (1990)

$$
\text { b }=(15 \times N)^{0.3}+15<45
$$

c. Hatanaka Uchida (1996)

$$
b=(20 \times N)^{0.3}+20
$$

d. Moustafa Abdou Abdel Naeim Mahmoud (2013)

$$
b=0.209 * N+19.60
$$


Tabel 4 Sudut geser berbagai jenis tanah

\begin{tabular}{|l|c|}
\hline \multicolumn{1}{|c|}{ Jenis Tanah } & Sudut Geser Dalam (Ø) \\
\hline Kerikil kepasiran & $35^{\circ}-40^{\circ}$ \\
\hline Kerikil kerakal & $35^{\circ}-40^{\circ}$ \\
\hline Pasir padat & $35^{\circ}-40^{\circ}$ \\
\hline Pasir lepas & $30^{\circ}$ \\
\hline Lempung kelanauan & $25^{\circ}-30^{\circ}$ \\
\hline Lempung & $20^{\circ}-25^{\circ}$ \\
(Sumber : Das, Soil Mechanics $7^{\text {th }}$ edition, 2010)
\end{tabular}

\section{Permeabilitas}

Sifat ini untuk mengukur/menentukan kemampuan tanah dilewati air melalui pori-porinya. Sifat ini penting dalam konstruksi bending tanah urugan dan persolan drainase. Adapun permeabilitas dari berbagai jenis tanah antara lain sebagai berikut :

Tabel 5 Nilai Permeabilitas berdasarkan jenis tanah

\begin{tabular}{|l|l|l|}
\hline \multirow{2}{*}{ Soil Type } & $\mathrm{K}$ \\
\cline { 2 - 3 } & $\mathrm{cm} / \mathrm{sec}$ & $\mathrm{ft} / \mathrm{min}$ \\
\hline Clean gravel & $100-1.0$ & $200-2.0$ \\
\hline Coarse sand & $1.0-0.01$ & $2.0-0.02$ \\
\hline Fine sand & $0.01-0.001$ & $0.02-0.002$ \\
\hline Silty sand & $0.001-0.00001$ & $0.002-0.00002$ \\
\hline Clay & $<0.00001$ & $<0.000002$ \\
\hline
\end{tabular}

(Sumber :Princiles of Geotechnical Engineering Ed. $7^{\text {th }}$ )

\section{Modulus Young}

Modulus elastisitas adalah angka yang digunakan untuk mengukur objek atau ketahanan bahan untuk mengalami deformasi elastis ketika gaya diterapkan pada benda itu. Modulus elastisitas satu benda didefinisikan sebagai kemiringan dari kurva tegangan-rengan di wilayah deformasi elastis. Bahan kaku akan memiliki modulus elastisitas yang lebih tinggi. Tanah juga memiliki nilai modulus elastisitas.

Secara empirik, nilai Modulus Young tanah kohesif dapat dicari dengan persamaan berikut (Sumber : Bowles J.E., 1996) :

1. Hubungan modulus elastisitas (Es) dengan undrained cohesion clays $(\mathrm{Cu})$ untuk tanah clay:

$$
E s=(300 \text { to } 1500) * C t
$$

2. Hubungan modulus elastisitas (Es) dengan nilai N-SPT untuk pasir :

$$
E s=(350 \text { to } 500)+\log (N)+98,1
$$


Tabel 6 Korelasi nilai N-SPT terhadap nilai koefisien dari berbagai jenis tanah

\begin{tabular}{|l|l|l|l|}
\hline \multirow{5}{*}{ Tanah Lempung } & Jenis Tanah & Nilai $\mathrm{n}$ & Nilai Koefisien \\
\cline { 2 - 4 } & Very soft clay & $0-2$ & $500-666.7$ \\
\cline { 2 - 4 } & Soft clay & $2-4$ & $666.7-833.4$ \\
\cline { 2 - 4 } & Medium stiff clay & $4-8$ & $833.4-1000.1$ \\
\cline { 2 - 4 } & Stiff clay & $8-15$ & $1000.1-1166.8$ \\
\cline { 2 - 4 } Tanah Pasir & Very stiff clay & $15-30$ & $1166.8-1333.5$ \\
\cline { 2 - 4 } & Hard clay & $30-120$ & $1333.5-1500$ \\
\hline \multirow{5}{*}{} & Very loose & $0-4$ & $350-380$ \\
\cline { 2 - 4 } & Loose & $4-10$ & $380-410$ \\
\cline { 2 - 4 } & Medium & $10-30$ & $410-440$ \\
\cline { 2 - 4 } & Dense & $30-50$ & $440-470$ \\
\cline { 2 - 4 } & Very Dense & $50-100$ & $470-500$ \\
\hline
\end{tabular}

(Sumber: Bowles J.E., 1996)

\section{Poisson's Ratio}

Poisson's Ratio adalah sebuah konstanta elastic yang merepresentasikan sifat fisis batuan. Seperti contoh sebuah sampel batuan yang berbentuk silinder dengan panjang $L$ dan jari-jari R. Apabila sampel tersebut ditekan dengan gaya berkekuatan F maka karena tekanan tersebut panjang sampel akan memendek dan jari-jarinya akan melebar. Jika perubahan panjangnya adalah dL dan perubahan jari-jarinya adalah dR, maka besaran Poisson's Ratio adalah dR/dL.

Poisson's Ratio nilai perbandingan antara regangan horizontal dengan regangan vertikal.

Keterangan :

$$
\nu=\frac{\varepsilon_{k}}{\varepsilon_{r}}
$$

$\begin{array}{ll}\boldsymbol{\varepsilon}_{\boldsymbol{h}} & =\text { regangan horizontal } \\ \boldsymbol{\varepsilon}_{\boldsymbol{v}} & =\text { regangan vertical }\end{array}$

Tabel 7 Poisson's Ratio berbagai jenis tanah

\begin{tabular}{ccc}
\hline Tipe Tanah & Deskripsi & $\left(v^{\prime}\right)$ \\
\hline Clay & Soft & $0,35-0,40$ \\
& Medium & $0,30-0,35$ \\
\multirow{2}{*}{ Sand } & Stiff & $0,20-0,30$ \\
& Loose & $0,15-0,25$ \\
& Medium & $0,25-0,30$ \\
& Dense & $0,25-0,35$
\end{tabular}

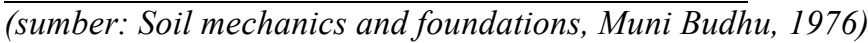

\section{Prefabricated Vertical Drain}

PVD umumnya berbentuk pita dengan sebuah inti plastik beralur terbuat dari material geosintesis (material polimer) yang dibentuk seperti potongan yang panjang. Material 
polimer dapat berupa Material PVC dengan lebar 90 sampai $100 \mathrm{~mm}$, ketebalan 2 sampai 6 mm.PVD dibuat dalam bentuk gulungan serta dipasang dengan minyak khusus sehingga dapat terlindung dari tekanan hidrolik tanah (Gulhati, Shaskhi K. 2005). Gambaran lebih jelasnya dapat dilihat pada Gambar 1

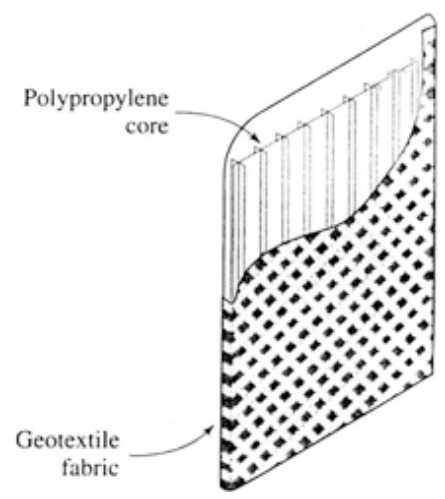

Gambar 1 Prefabricated Vertical Drain

Jika menggunakan PVD, maka karekteristik hidroliknya harus diperhatikan dengan seksama, misalnya mengenai kapasitas pengeluaran air dan permeabilitas dari filter dan kuat tekuk serta ketahanannya terhadap degradasi fisik dan biokimia dalam berbagai kondisi cuaca dan lingkungan yang tidak ramah.

PVD dibuat untuk menggantikan penggunaan sand drain. PVD dipasang dengan tidak dibor, sehingga penginstalan dapat berlangsung dengan cepat (Das, Braja M. 2002).

PVD biasanya dipasang sampai kedalaman hingga $30 \mathrm{~m}$ dengan menggunakan rig penetrasi statis. Untuk yang lebih dalam dibutuhkan rig yang lebih besar untuk mempermudah proses penetrasi.

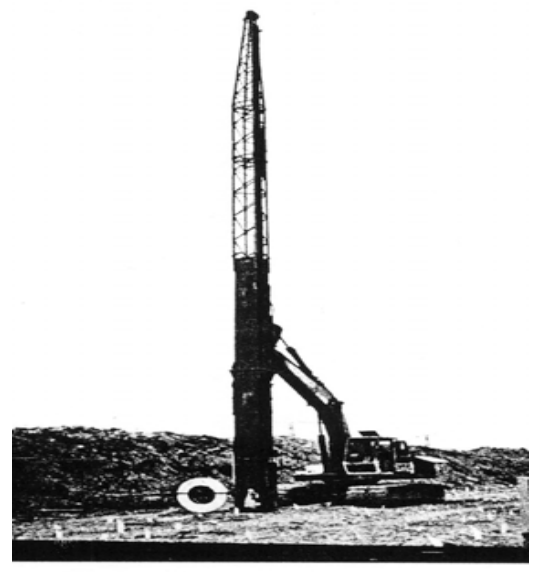

Gambar 2 Pemasangan PVD

Sistem vertical drain dengan PVD harus dipasang dengan mandrel yang ujungnya tertutup (closed-end mandrel) yang dimasukkan ke dalam tanah baik dengan penetrasi statis maupun pemancangan dengan vibrator. Tingkat kerusakan atau gangguan pada tanah yang ditimbulkannya bergantung pada bentuk dan ukuran dari mandrel dan sepatu yang dapat dilepaskan (detachable shoe) pada dasar mandrel, yang digunakan untuki mengangkut material ini ke dalam tanah. 
Pelaksanaan pemasangan PVD adalah dengan memasang lantai kerja dengan ketebalan yang cukup yang dapat mendukung beban peralatan.Kemudian satu jalur selimut pasir dihampar dan PVD dapat dipasang melaluinya sedangkan peralatan berdiri di atas pasir tersebut. Alat pancang kemudian mundur, dan lapisan selimut pasir berikutnya dihampar dan selanjutnya proses pemasangan diulangi. Proses ini dapat dilihat pada Gambar 3.

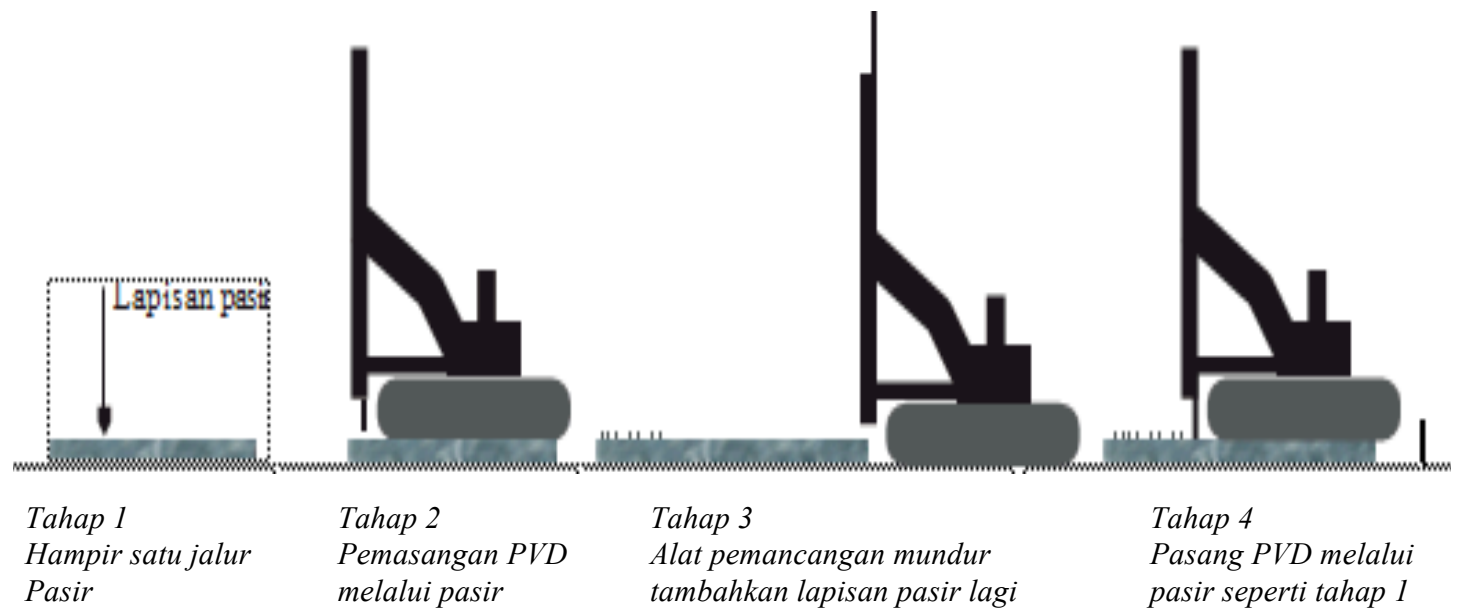

Gambar 3 Prosedur instalasi PVD menembus selimut pasir

Parameter dari PVD berkaitan dengan berbagai faktor yang mempengaruhi sifat mekanis dan sifat penyaringan tanah yang dapat dijelaskan sebagai berikut:

1. Settlement, S (m) bisa didapat dari penyelidikan tanah di laboratorium dan perhitungan mekanika tanah. Sedangkan hubungan besarnya kedalaman tanah yang akan dipasang PVD (Hc) dengan settlement $\mathrm{S} / \mathrm{Hc}$ (\%)mengindikasikan tingkat kompresibilitas daritanah.

2. Ketebalan dari lapisan Hc bersamaan dengan kelebihan dari tekanan pori menunjukkan tekanan horizontal total di atasdrainase.

3. Kedalaman dari landfill, $\mathrm{H}(\mathrm{m})$, bersamaan dengan laju dari penurunan, dH/dt $(\mathrm{m} / \mathrm{s})$, dan permeabilitas dari tanah, menunjukkan derajat dari kelebihan tekanan pori.

4. Waktu konsolidasi $\mathrm{T}_{90}$ dapat diperoleh dari percobaan laboratorium. Dalam hubungan dengan jarak $\mathrm{L}_{\mathrm{eq}}(\mathrm{m}), \mathrm{T}_{90}$ (tahun) dikonversikan $\mathrm{ke} \mathrm{L}_{\mathrm{eq}}$ standar $=2.5 \mathrm{~m}$ yang memberikan indikasi permeabilitas (R.Veldhuijzen VanZanten,1986).

Secara teoritis, jarak standar PVD $2.5 \mathrm{~m}$ tersebut diusulkan dengan maksud untuk mempermudah memperoleh nilai suatu pembanding pada keadaan tanah yang berbeda. Nilai pembanding tersebut diwakilkan dengan y.

$$
\mathrm{T}_{90}^{2.5}=\psi \times \mathrm{T}_{90}
$$

Dimana $\mathrm{T}_{40}^{2.5}=$ waktu konsolidasi dengan jarak drainase standar $\mathrm{L}_{\mathrm{eq}} 2.5 \mathrm{~m}, \mathrm{~B}=$ Lebar PVD

$$
\psi=\left(\frac{2.5}{L}\right)^{2} \frac{\mu(\mathrm{L}=2.5 \mathrm{~m})}{\mu(\mathrm{L})}
$$




$$
\begin{aligned}
& (L)=\frac{n^{2}}{n^{2}-1}\left\{\ln (u)-0.75+\frac{1}{n^{2}}\left(1-\frac{1}{4 n^{2}}\right)\right\} \\
& \mathrm{n}=\left(\frac{\mathrm{L}}{\mathrm{deq}}\right) \\
& \mathrm{d}_{\mathrm{eq}}=\frac{2 \mathrm{~B}}{\pi}
\end{aligned}
$$

Prefabricated Vertical Drain (PVD) adalah lembaran plastik untuk drainase vertikal yang panjang dan berkantung yang merupakan kombinasi antara bahan inti (core) polypropylene berkekuatan mekanik tinggi dan lapisan pembungkus dari bahan geotekstil.

PVD bertujuan untuk mempercepat penurunan tanah (konsolidasi).Konsolidasi pada PVD terjadi pada arah horizontal dan arah radikal.

$$
\boldsymbol{U}=\mathbf{1}-\left[\left(\mathbf{1}-\boldsymbol{U}_{\boldsymbol{v}}\right) *\left(\mathbf{1}-\boldsymbol{U}_{\boldsymbol{r}}\right)\right]
$$

Keterangan

$\mathrm{U}=$ Derajat konsolidasi total

$\mathrm{Ur}=$ Derajat konsolidasi arah radikal

$\mathrm{Uv}=$ Derajat konsolidasi arah vertical

Konsolidasi arah vertikal :

$$
\begin{aligned}
& T_{v}=t * \frac{C_{v}}{H_{d r}^{2}} \\
& T_{v} \leq 0.2 ; U_{v}=\sqrt{\frac{4 T}{\pi}} \\
& T_{v} \geq 0.2 ; U_{v}=1-\frac{8}{\pi^{2}} * e^{\frac{-\pi^{2} T}{4}}
\end{aligned}
$$

Keterangan

$\mathrm{Tv}=$ Time factor (arah vertikal)

$\mathrm{t} \quad=$ Waktu yang dibutuhkan untuk konsolidasi arah vertikal

$\mathrm{Cv}=$ Koef. Konsolidasi arah vertikal

$\mathrm{Hdr}=$ Panjang pengaliran arah vertical

Rumus konsolidasi vertikal ini juga digunakan untuk mencari konsolidasi tanpa PVD. Konsolidasi arah radial :

$$
\begin{aligned}
& T_{r}=t * \frac{C_{h}}{d^{2}{ }_{e}} \\
& \mathrm{U}_{\mathrm{r}}=1-\exp \left[-\frac{8 \mathrm{~T}}{\mathrm{~F}(\mathrm{n})}\right]
\end{aligned}
$$




$$
\begin{aligned}
& F(n)=\frac{n^{2}}{n^{2}-1} * \ln (n)-\frac{3 n^{2}-1}{4 n^{2}} \\
& n=\frac{d_{e}}{d_{w}} \\
& d_{w}=\frac{2(a+b)}{\pi}
\end{aligned}
$$

Keterangan

$\operatorname{Tr}=$ Time factor (arah radial)

$\mathrm{t} \quad=$ Waktu yang dibutuhkan untuk konsolidasi arah radial

$\mathrm{Ch}=$ Koef. Konsolidasi arah vertikal

de $=$ Diameter area silindris drainase (1.05s untuk konfigurasi segitiga, 1.13s untuk konfigurasi bujur sangkar)

$\mathrm{dw}=$ Diameter ekivalen PVD

$\mathrm{F}(\mathrm{n})=$ Faktor jarak drain

$\mathrm{a} \quad=$ Lebar PVD

$\mathrm{b} \quad=$ Ketebalan PVD

\section{Metodologi}

a. Melakukan studi literatur mengenai reklamasi, konsolidasi, dan analisis stabilitas yang bersumber dari paper, buku-buku geoteknik, internet, dan laporan Tugas Akhir alumni.

b. Mengumpulkan data-data tanah yang diperlukan, seperti : nilai N-SPT, sondir, soil investigation, kemudian digunakan untuk menentukan parameter tanah seperti undrained shear strength, koefisien konsolidasi, parameter tegangan.

c. Menentukan ketinggian setiap timbunan yang efektif.

d. Menghitung penurunan tanah, dengan data-data lapisan tanah yang ada dengan vertical drain.

e. Melakukan pemodelan dan menghitung stabilitas tanah dengan memasukkan input data yang sudah dihitung sebelumnya, dengan bantuan perangkat lunak PLAXIS.

\section{Analisis dan Pembahasan}

Parameter tanah didapat melalui korelasi nilai N-SPT dari berbagai sumber, maka disajikan

\begin{tabular}{|c|c|c|c|c|c|}
\hline & & Jenis Tanc & & & \\
\hline & & Lapisan 1 & Lapisan 2 & Lapisan 3 & Lapisan 4 \\
\hline & Tebal (m) & 20 & 10 & 20 & 13.75 \\
\hline & N-SPT & 1.818 & 6.6 & 13 & 16.375 \\
\hline Sifat Imum & Vunsat (KN/m3) & 14 & 16.489 & 16.3 & 21.464 \\
\hline & Ysat (KN/m3) & 18.454 & 18.95 & 21.14 & 0.00036 \\
\hline Permeabilitas & $\mathrm{kx}$ (m/hari) & 0.000036 & 0.000198 & 0.000279 & 0.00036 \\
\hline
\end{tabular}
dalam tabel berikut.

Tabel 8 Daftar parameter tanah 


\begin{tabular}{|c|c|c|c|c|c|}
\hline & & \multicolumn{4}{|c|}{ Jenis Tanah } \\
\hline & & Lapisan 1 & Lapisan 2 & Lapisan 3 & Lapisan 4 \\
\hline & ky (m/hari) & 0.000036 & 0.000198 & 0.000279 & 0 \\
\hline \multirow{2}{*}{ Kekakuan } & Eref $(\mathrm{KN} / \mathrm{m} 2)$ & 0 & 0 & 0 & 0.2 \\
\hline & $\mathrm{v}$ & 0.4 & 0.35 & 0.3 & 0 \\
\hline \multirow{3}{*}{ Kekuatan } & $\mathrm{c}(\mathrm{KN} / \mathrm{m} 2)$ & 0 & 0 & 0 & 30.73213 \\
\hline & sudut geser $\left(^{\circ}\right)$ & 20.72049 & 25.89954 & 30.29706 & 0 \\
\hline & sudut dilantasi $\left(^{\circ}\right)$ & 0 & 0 & 0 & 269.3688 \\
\hline Tegangan Vertikal & $\sigma \mathrm{v}=\mathrm{V} . \mathrm{H}(\mathrm{kN} / \mathrm{m} 2)$ & 280 & 164.89 & 326 & 0 \\
\hline Tegangan air pori & $\mu=\gamma w . H(k N / m 2)$ & 0 & 0 & 0 & 164.5 \\
\hline Tegangan Vert. Efektif & $\sigma^{\prime} \mathrm{v}=\sigma \mathrm{v}-\mu(\mathrm{kN} / \mathrm{m} 2)$ & 200 & 100 & 200 & 0 \\
\hline
\end{tabular}

Lapisan 1 = Clay Very to Soft

Lapisan 2 = Clay Medium Soft

Lapisan 3 = Clay Medium Soft to Stiff

Lapisan 4 = Clay Stiff

Tabel 9 Daftar Parameter PVD

\begin{tabular}{|ll|}
\hline Jenis & Ukuran \\
\hline Dimensi PVD & $: 100 \mathrm{~mm} \mathrm{x} 4 \mathrm{~mm}$ \\
\hline Jarak antar PVD (s) & $: 1.3 \mathrm{~m}$ \\
\hline Kedalaman instalasi & $: 30 \mathrm{~m}$ \\
\hline $\mathrm{kh} / \mathrm{ks}$ & $: 3$ \\
\hline
\end{tabular}

Studi kasus dari penelitian ini merupakan proyek Reklamasi Pelabuhan Kontainer Belawan. Kondisi tanah berupa tanah lempung sangat lunak dengan ketebalan $20 \mathrm{~m}$, dibawah merupakan tanah lempung lumayan lunak dengan ketebalan $10 \mathrm{~m}$, kemudian dibawahnya merupakan tanah lempung lumayan lunak ke kaku dengan ketebalan $20 \mathrm{~m}$. dan terakhir dibawahnya merupakan tanah lempung kaku dengan ketebalan $16.45 \mathrm{~m}$. PVD dipasang sedalam $30 \mathrm{~m}$ hingga mencapai tanah lempung lumayan lunak dengan jarak pemasangan 1.3 $\mathrm{m}$ menggunakan pola triangular.

Studi kasus yang akan dilakukan adalah pemodelan kondisi ekisisting dengan dua lapisan tanah lunak menggunakan hardening soil model dengan metode ekuivalen plane strain. Berikut adalah pemodelan pada program PLAXIS 2DPembahasan berikut ini akan merencanakan gelegar memanjang (girder) pada jembatan 24 meter berdasarkan beban dari SNI 1725:2016 Pembebanan untuk Jembatan. Adapun data jembatan dapat dilihat dibawah ini : 


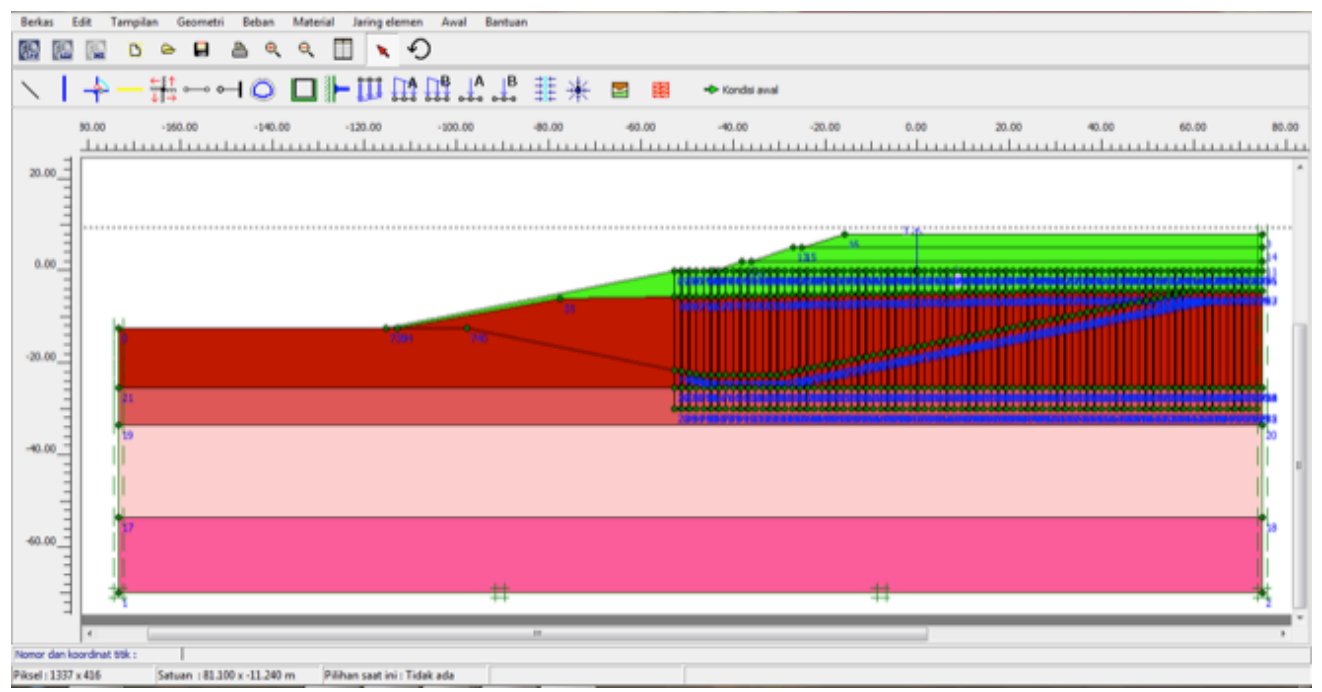

Gambar 3 Pemodelan pada PLAXIS dengan PVD

Adapun tahapan perhitungan dalam PLAXIS 2D terdiri dari 9 phase seperti pada Tabel 4. Pada tahapan ini, besar penurunan dan waktu penurunan dihitung.

Tabel 4 Tahapan pemasangan PVD dan Preloading

\begin{tabular}{|l|l|l|}
\hline No & Tahapan Pekerjaan & Waktu (hari) \\
\hline 1 & Dredging & - \\
\hline 2 & Reklamasi & 30 \\
\hline 3 & PVD & 14 \\
\hline 4 & Preloading 1 & 7 \\
\hline 5 & Konsolidasi 1 & 45 \\
\hline 6 & Preloading 2 & 7 \\
\hline 7 & Konsolidasi 2 & 45 \\
\hline 8 & Preloading 3 & 7 \\
\hline 9 & Konsolidasi 3 & 98.5 \\
\hline
\end{tabular}

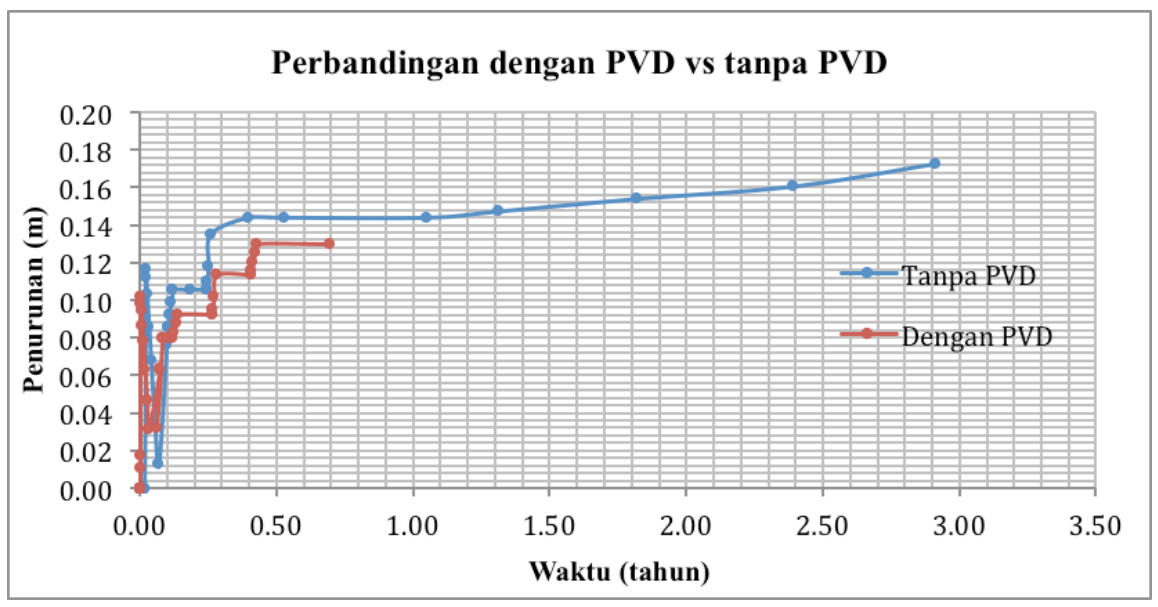

Gambar 4 Perbandingan penurunan dengan PVD dan tanpa PVD 
Berdasarkan pemodelan eksisting dan tahapan pemasangan PVD, proses running metode ekuivalen plane strain di atas dilakukan dalam PLAXIS 2D. Hasil analisis penurunan diperoleh akan dibandingkan dengan pengukuran dilapangan. Perbandingan tersebut dapat dilihat pada Gambar 4 yang menunjukkan grafik penurunan hasil analisis metode ekuivalen plane straindan hasil pengukuran di lapangan.

\section{Kesimpulan}

Berdasarkan analisis diatas dapat disimpulkan :

1. Perhitungan PLAXIS dilakukan 2 kali, yaitu dengan PVD dan tanpa PVD, dengan tinggi timbunan sebagai berikut : $2 \mathrm{~m}, 3 \mathrm{~m}, 3 \mathrm{~m}$.

2. Lama konsolidasi perhitungan PLAXIS menggunakan PVD adalah 209.5 hari, yang artinya jauh lebih efisien dibanding perhitungan PLAXIS tanpa PVD yang memerlukan waktu hingga 1063 hari.

3. Lama konsolidasi perhitungan manual menggunakan PVD adalah 73 hari, dan perhitungan manual tanpa PVD adalah 27552.74 hari.

4. Tahapan konstruksi yang dilakukan sebagai berikut : dredging, reklamasi, pemasangan PVD, preloading tahap 1, konsolidasi tahap 1, preloading tahap 2, konsolidasi tahap 2, preloading tahap 3, konsolidasi tahap 3.

5. SF konsolidasi tahap $1=3.13$

SF konsolidasi tahap $2=2.97$

SF konsolidasi tahap $3=2.57$

\section{Daftar Pustaka}

Abrahamson N, Silva. (1996). Empirical Ground Motion Models. New York: Brookhaven National Laboratory.

Abramson, L. W., Lee, T. S., Sharma, S., \& Boyce, G. M. (2002). Slope stability and stabilization methods. John Wiley \& Sons.

Bowles, L. E. (1996). Foundation analysis and design. McGraw-hill.

Chai, J. C., Shen, S. L., Miura, N., \& Bergado, D. T. (2001). Simple method of modeling PVDimproved subsoil. Journal of Geotechnical and Geoenvironmental Engineering, 127(11), 965-972.

Das, B. M. (2010). Principles of Geotechnical Engineering, Cengage Learning. Stamford, Connecticut.

Duncan, J. M., Wright, S. G., \& Brandon, T. L. (2014). Soil strength and slope stability. John Wiley \& Sons.

Han, J. (2015). Principles and practice of ground improvement. John Wiley \& Sons.

Indraratna, B., Bamunawita, C., Redana, I., \& McIntosh, G. (2003). Modelling of prefabricated vertical drains in soft clay and evaluation of their effectiveness in practice. Journal of Ground Improvement, 7(3), 2003, 127-138.

Terzaghi, K., Peck, R. B., \& Mesri, G. (1996). Soil mechanics in engineering practice. John Wiley \& Sons.

William Lambe, T., \& Whitman, R. V. (1969). Soil mechanics.Massachusetts Instihute of Technology, 406-422. 
